\title{
Perceptions of Adolescents and Health Workers Towards Adolescents' TB Diagnosis in Central Uganda: A Cross-Sectional Qualitative Study
}

\author{
Winters Muttamba (ID) \\ Mudarshiru Bbuye (D) \\ Joseph Baruch Baluku (1D ${ }^{1,2}$ \\ Stephen Kyaligonza' \\ Joanitah Nalunjogi' \\ Ivan Kimuli' \\ Bruce Kirenga ${ }^{1,3}$ \\ 'Makerere University Lung Institute, \\ College of Health Sciences, Makerere \\ University, Kampala, Uganda; \\ ${ }^{2}$ Department of Medicine, Mulago \\ National Referral Hospital, Kampala, \\ Uganda; ${ }^{3}$ Division of Pulmonary \\ Medicine, College of Health Sciences, \\ Makerere University, Kampala, Uganda
}

Correspondence: Winters Muttamba Makerere University Lung Institute, College of Health Sciences, Makerere University, P.O Box 7749, Kampala, Uganda

$\mathrm{Tel}+256772512261$

Email muttamba@gmail.com
Purpose: Prompt diagnosis of TB among adolescents may reduce transmission and improve individual outcomes. However, TB diagnosis in adolescents is challenging. This study sought to understand challenges to adolescent TB diagnosis.

Methods: We conducted qualitative focus group discussions (FGDs) to explore adolescents' and health workers' perspectives on challenges to TB diagnosis among adolescents seeking care at four secondary health care facilities in Uganda. Eight FGDs were conducted: four with 32 adolescents consulting for medical care and four with 34 health workers involved in TB care.

Results: Adolescents were aware of TB and associated risk factors and believed behaviours like smoking and alcohol use are risk factors for TB. They reported school schedules limit them from seeking TB care and have to miss school or wait for holidays to seek TB diagnosis. They noted school nurses do not take much interest in diagnosing TB and do not refer them to hospitals for further evaluation when they present with TB symptoms. Furthermore, adolescents reported cross-cutting issues like loss of trust in public health systems, encountering unfriendly, judgmental and uncooperative health workers. Health workers mentioned the school environment exposes adolescents to TB as the dormitories they sleep in are overcrowded. They indicated that it was difficult to make a diagnosis of TB in adolescents as the adolescents do not disclose health information. They reported fellow health workers perceive adolescents as being at low risk of TB as they believe most often adolescents are HIV negative and thus have reduced risk of TB.

Conclusion: Adolescents present unique challenges that need to be addressed if TB diagnosis is to improve. These challenges could be handled by interventions that lead to minimal disruptions on school schedules, provision of adolescent-friendly services and intervention to build capacity of health care workers in the provision of adolescent-friendly services.

Keywords: adolescent TB, adolescent health, school schedules, adolescent friendly TB services

\section{Introduction}

Tuberculosis (TB) is a major public health concern and is one of the top ten causes of death worldwide. ${ }^{1}$ In 2020 , up to 5.8 million TB notifications were reported. ${ }^{2}$ In the same year, 1.3 million TB deaths among HIV negative people and 214,000 people living with HIV were recorded. ${ }^{2}$ Though TB is preventable and curable, it continues to negatively impact the lives and development of many children and adolescents across the world.

The prevalence of TB in adolescents is likely higher. Indeed, some studies have demonstrated a high prevalence in adolescents. ${ }^{3}$ With majority of the world's 
adolescent population living in low- and middle-income countries where the prevalence of TB is very high, this is hardly surprising. Despite the increased risk of TB among adolescents, this group is still not considered as a priority group in TB control programs. Emerging evidence suggests that the prevailing approaches do not meet the needs of adolescents ${ }^{4-6}$ Adolescents are more likely to be missed by TB systems than other age groups, according to recent TB prevalence surveys in Africa, eg a subanalysis from Uganda's prevalence survey database indicated that of the 7506 adolescent participants (15-19 years), 3.8\% reported a chronic cough with only $56.0 \%$ seeking care for their chronic cough compared to adults at $62.7 \%{ }^{7}$ Current reporting systems do not report outcomes separately for adolescents, ${ }^{8}$ a barrier to designing targeted interventions. Strategies that put adolescent health at the centre stage rather than focus on specific health agendas provide opportunities to improve the health of adolescents now and in the future. ${ }^{9}$ The World Health Organization recently published a roadmap towards ending $\mathrm{TB}$ in children and adolescents. $^{8}$

To fill knowledge gaps that exist on challenges to adolescent TB control, we set out to explore the perceptions of health care workers and adolescents seeking TB diagnosis in urban and rural health facilities in Uganda.

\section{Materials and Methods Study Design}

This was a cross-sectional qualitative study. We carried out a qualitative study involving focus group discussions with adolescents with $\mathrm{TB}$ and the health care providers to identify barriers and facilitators to TB diagnosis among adolescents in Uganda.

\section{Study Setting}

We enrolled participants from two urban health centres in Luweero and Wakiso districts and two rural health centres in Nakaseke and Gombe districts in central Uganda. These public-sector facilities offer health services free of charge, act as referral centres for lower-level health facilities, and each has a TB diagnostic and treatment unit (DTU), in addition to providing other medical and surgical services. Diagnosis of TB is through bacteriological tests and radiology (chest X-ray). The bacteriological tests mainly used are smear microscopy, nuclear amplification tests (Xpert assay) and culture. ${ }^{10}$ In public health facilities, these tests are all provided free of charge, while in private health facilities, they are availed at a cost. Patients, including adolescents are at liberty to choose which facilities to visit. Uganda is a high burden TB and HIV/TB country. ${ }^{2}$ Less than one-fifth of patients with chronic cough are investigated by either sputum and/or CXR examination in Uganda. ${ }^{7}$

\section{Sampling and Study Participants}

Researchers (WM, MB) visited four TB treatment units in the selected health facilities between July 2018 and September 2018. Together with the facility TB focal persons, they identified and invited health workers providing TB care in the health facility and adolescents visiting the TB treatment unit for medical care to participate in separate FGDs. We purposively recruited 32 adolescents aged 10-19 years attending the 4 health facilities for health care consultations. Purposive sampling enabled appropriate gender representation and also ensured we included adolescents conversant in Luganda and English languages. Participants were selected on the day of data collection. We included adolescents that were either seeking care for cough-related symptom at the health facilities or those who had previously been investigated for TB. These adolescents were drawn from the TB clinics and medical outpatient clinics. We also recruited 34 health workers at the 4 health facilities who reported prior interactions with an adolescent while offering a health service. The health workers included clinical officers, nurses, counsellors, community linkage facilitators and laboratory technicians.

\section{Data Collection}

We invited participants to take part in FGDs at the health facilities. The discussions were facilitated by two male researchers (WM and $\mathrm{MB}$ ) with training and experience in qualitative research. The two (one in his late 20s and the other in his 30s) were conversant in both English and the local language (Luganda). Participants were free to participate in either language during the discussion. The discussions were guided by an FGD guide that had previously been piloted in another health facility. The guide was informed by GLOBAL STANDARDS FOR QUALITY HEALTHCARE SERVICES FOR ADOLESCENTS ${ }^{9}$ using questions covering health literacy, community support, package of services, provider competencies, facility characteristics and adolescent participation. The discussions lasted 45-60 minutes and the responses were recorded on two audio recorders. While the facilitator led the discussion, the notetaker took field notes during the 
discussion. At the end of the discussion, the facilitator and notetaker reviewed the notes to agree on the interpretation. They also noted emerging domains/themes and adapted the guide by expanding the probes in subsequent discussions. The FGDs were stopped once thematic saturation was achieved.

\section{Analysis}

The audio recordings were transcribed. The transcribed files were read twice by the investigator (WM) who familiarized himself with the collected data. WM generated memos while going through the transcripts. All data was entered in Atlas.ti version 8.5 and first cycle open coding done, with codes developed using an inductive approach to content analysis. Thereafter, second cycle coding was done and the codes revised and collapsed. The collapsed codes were then reviewed and finalized with colleagues undertaking training in qualitative research, and code categories generated. These codes were later applied to all transcripts. From the grouped codes, themes that emerged were obtained and thereafter thematic content analysis was done. Verbatim quotes central to the emerging themes were identified and used to illustrate the themes and findings.

\section{Human Subjects and Ethics Approval}

All participants provided informed verbal consent, with caretakers giving consent for participants aged below 18 years. The respondents received assurance that their responses would be anonymized during dissemination. Approval for the study was granted by Mulago Hospital Ethics Review Committee (MHREC 1481) and administrative clearance obtained from the management of the health facilities.

\section{Results}

Between June 2018 and July 2018, we conducted 8 focus group discussions with 32 adolescents (15 males, 17 females) and 34 health care workers. The average age of the adolescents was 16 years (standard deviation=1.8 years) and $65 \%(21 / 32)$ of them were in school. Of the adolescents included, 8 had previously been treated for $\mathrm{TB}$, while 24 were being investigated for TB. We included 34 health workers (i.e 3 clinical officers, 4 enrolled midwives, 4 nursing officers, 4 laboratory technicians, 4 TB focal persons, 4 senior nursing officers, 2 enrolled nurses, 5 community linkage facilitators and 4 counsellors).

\section{Perceptions of the Adolescents}

Adolescent participants described challenges related to TB in several thematic areas, including fear of diagnosis, perceived and experienced poor health worker attitudes, lack of concern regarding cough as a symptom, and frustration with seeking health care at public health facilities. The parental role in supporting health care seeking also emerged. In the text that follows, we expand on these themes, with corresponding quotes from the adolescents.

\section{Knowledge and Risk of TB}

Adolescents described their knowledge of TB with emphasis on risk factors and behaviours for acquiring the disease. It is generally known that the adolescence period is a time of experimenting for many adolescents and some end up taking on risky behaviours. The adolescents noted smoking and drinking as behaviours that could increase their risk for TB:

Some of our friends engage in drinking alcohol and smoking which can lead to contracting TB. 19-year-old Male; Entebbe Hospital

They also associated heavily congested hospitals and other crowded places with increased risk for TB. They described waiting in long lines with coughing people who might expose them to $\mathrm{TB}$ as a high risk for $\mathrm{TB}$ acquisition.

The places we move in such as bars, slums, and crowded people e.g. in hospitals exposes someone to TB. 17-yearold Female; Entebbe Hospital

The adolescents did not perceive cough symptoms as serious. They reported that when they have a cough, they typically visit private clinics, pharmacies or use herbs.

For me when I got the cough, I used herbal medicine and I became ok. 15-year-old Male; Entebbe Hospital:

The adolescents mentioned several barriers that stand in their way of care. Much as some were cross-cutting and affect adults as well, there were those unique to the adolescents. These include;

\section{Conflicting School Schedules}

They mentioned healthcare-seeking interrupts their school schedules and increases transport costs. Adolescents have to miss school or use school holidays to be able to visit the health facilities for care.

Musawo, as I said it may be a chance, you may come early .... like now I came at around 9 am, but by now 
$(1: 30 \mathrm{pm})$, the pharmacy is still closed thus you cannot get medication so I have been here waiting, by now I cannot go to school so I have missed school today. 18-year-old Male; Luwero Health Centre IV:

Adolescents noted they have to forego school or come to health facilities during holidays. When they do find the time to come to the health care facilities, they experience disappointment when they do not get the full care they need and are occasionally asked to return to the health facilities. This caused them to avoid health facilities.

If they don't work on me, I may take my time because I also have to go to school, probably I will come back in the next holidays because I have tried to come in this holiday when it has just started. 18-year-old Female; Luwero Health Centre IV

\section{The Limited Capacity of the School Health System to Diagnose TB}

Some adolescents go to schools that have school sick bays managed by a school nurse. Despite the presence of these sick bays, adolescents reported dissatisfaction with the competency of the school health system regarding diagnosis of TB. They noted that the school nurses do not seem to take much interest in the well-being of students, and do not refer them to hospitals for thorough diagnosis and evaluation.

.... another thing, some of us find ourselves at school. When that cough gets you ....you know at school we have the health workers cough can get you and gets you for a long period or even when it has just got you and you go to say the school nurse, they don't care knowing much, they just ask you what is paining you and you say cough then she gives you drugs and then you stay there and they don't even allow you to go home to get to a hospital. 17year-old Female; Gombe hospital.

The adolescents also reported barriers that cut across and affect the adults as well. These include;

\section{Health Systems Challenges}

The adolescents reported encountering health workers who were unfriendly, judgmental or uncooperative, do not explain procedures to them and prescribe treatment that they have to buy. Adolescents felt health workers judged them unfairly for delaying visits to the health facility. They described the attitude of health workers as demotivating.

... the problem is that when you reach hospital, every health worker has their attitude, some are easy, and others are difficult. For some you describe your situation and how you feel, then they bark at you that you have taken long without going to hospital and how you have been going to die. This demotivates one to come back. 18-yearold male from Nakaseke Health Centre IV

The adolescents who had previously been investigated for TB reported that health care workers did not offer them sufficient counselling about some of the things they needed to do as part of the TB investigation eg, explaining to them why they should provide a sputum sample and how it should be collected. They mentioned that most times they struggle to produce a sample as they at times have a non-productive cough.

.... for me if I get the right guidance and counselling, providing sputum may not be a problem as long as I have it, so the counselling would help to know why am giving the sputum. 17-year-old Female; Entebbe Hospital

\section{Fear of a TB Diagnosis}

The adolescents expressed fear of TB diagnosis. They feared the implications of the diagnosis, such as the long treatment period, the possibility of HIV, stigma associated with sputum mugs and masks, and discrimination. Some adolescents thought that a TB diagnosis might as well be HIV.

I was told I don't have TB. But also on giving me the results, I was fearful....... but they checked when I was fine, because I thought if they find me having TB, I may also have HIV. 16-year-old Female; Entebbe Hospital

Adolescents noted they were scared of having to be started on TB treatment if they were found TB positive. They associated TB treatment with long periods of injectable treatment.

For me the way they talk about TB treatment; I fear going for TB check-up. In our village they say that they inject you 60 injections as medicine for TB. Eehheehhheehh, people fear TB treatment that's why I fear. 16-year-old Male; Nakaseke Health Centre

Adolescents mentioned they are not comfortable moving around with the sputum mugs when the health workers give them these to go and provide a sputum sample.

for the adolescents, people don't want to see them holding the sputum container, you even hide behind buildings to try and produce the sputum. 18-year-old Male; Nakaseke Health Centre 


\section{Loss of Trust in Public Health Care Systems}

Some adolescents expressed frustration with public-sector health services, which they associated with stock-outs of key medicines.

.... for me what took me to the clinic is that when you go to government hospitals, they tell you there is no medicine and tell you to go buy at private pharmacies, and usually the medicines are very expensive, and also the lines there are long and you find yourself coughing in people, they all look at you and you feel out of place. So a person who goes to the clinic may be better because, they get the services faster though they have to pay money. 17-yearold Female; Entebbe Hospital

\section{Role of Parents}

The role of parents in supporting the adolescents in seeking care and diagnosis emerged with conflicting views from the adolescents. Whereas there are those that reported they are encouraged by their parents to seek care, there are those that mentioned their parents did not care.

For me they support me, even today they pushed me to come for checkup. 16-year-old Male; Luwero hospital

for me, its self-initiated, my parents seem not to care. 19 year-old Male; Luwero hospital

There are adolescents who suggested sensitisation and education of their parents in order to help with TB diagnosis and care.

they should sensitize and educate parents about adolescent TB, they can also go to schools.......Parents are key educators of their children. 19 year old female; Entebbe hospital

\section{Perceptions of Health Workers}

We also identified several themes regarding health workers' perceptions of TB diagnosis in adolescents. The themes include TB exposure at schools, uncooperative adolescents and health worker inadequacies. These themes are described in the subsequent text with relevant quotes.

\section{TB Exposure at Schools}

The health care workers perceived the environment at school exposes the adolescents to TB. They believed the living conditions at schools are fertile grounds for TB transmission.
Adolescents most cases are at school, they are always at school, imagine at school there is a biggest exposure, they are at risk, the dormitory is overcrowded, someone may be coughing without knowing whether he/she has TB. So all those children are at risk of getting TB, they are sleeping in the same dormitory, the dormitory is congested, may he/ she does not know because they are lacking knowledge concerning TB. Out Patient Department (OPD) TB nurse.

\section{Uncooperative Adolescents}

The health workers perceive diagnosis of TB in adolescents to be complicated by the fact that when they present, they withhold helpful information such as how long they have had a cough. This they noted was frustrating for them regarding making a diagnosis of $\mathrm{TB}$.

At times when they come to the hospitals, they don't say all. At times they hide this away from their parents. Even where they stay at times you find they have lived with someone who has ever had TB. Even as you take their history ... ok at times as you take their history, you find they are reserved. Even when you request for a lab test, some of them are a bit hesitant to give a sample. At times they want to be followed up all the way. OPD Nurse.

The health workers reported the adolescents do not want to be seen putting on masks and when they are given these masks they pocket them, hence exposing their peers to TB disease.

.........in trying to provide a mask, they look at it as being stigmatizing. Even when we explain why we use a mask. Even when you give them and they aren't escorted by an adult, he will have to pocket his mask...... he asks why is it only me putting on a mask. He may even reach the lab and sit down. A TB nurse mentioned.

\section{Health Worker Inadequacies Regarding TB Diagnosis in Adolescents}

The health workers also perceived adolescents to be at low risk of TB given the association between TB and HIV. They reported that many health workers may miss TB in adolescents because they associate TB with HIV and lowered immunity, which they did not believe to be common in adolescents.

I also think that we people who diagnose TB miss out on adolescents who have TB because we always think that for someone to have $\mathrm{TB}$, they must have low immunity or other accompanying factors, which is not easily thought of about adolescents. I can only think about TB when the 
adolescent has HIV otherwise, you be like no way this little girl may have TB so we normally treat other upper respiratory infection not thinking about TB. A clinician said.

In addition, the health workers reported barriers that not only hinder TB management in adolescents but also adults, largely pointing to health system limitations. For example, the health workers described large and overwhelmed facilities that could be difficult for adolescents to navigate.

This is a big hospital, patients come with a burden of diseases, so these patients need to find us (health workers) with a sober mind, not in disorganised mode. A nurse said.

The health workers mentioned they are few and most times the TB-related work is left to a few health workers as most of them do not want to do anything related to TB.

The biggest challenge I see since I came here is low interest in TB among staff, you find that every time you get the TB patient, you call the TB focal person, every time the TB focal person, most of these our colleagues, I don't know, but we fear a lot TB, we are not comfortable handling TB patients. A nurse at OPD said.

The health workers mentioned there are several myths in the community especially around the TB treatment period, which causes some adolescents to fear the diagnosis.

Also one of the things they worry about is the treatment, because there is still a myth in a community that treatment for TB takes a whole year, and it is tough, so it's usually their fears, for how long am I going to take medicine. A clinical officer reported.

\section{Discussion}

Studies in sub-Saharan Africa have found the prevalence of TB among adolescents and children to be high and cases frequently missed. A better understanding of the barriers to TB diagnosis among adolescents is necessary for improving TB control. Our qualitative study of perceptions of TB diagnosis among adolescents and health workers at urban and rural health facilities in central Uganda shows that TB diagnosis in adolescents is not only compounded by challenges unique to adolescents but also by challenges encountered by adults as well. Adolescents' unique challenges noted include the conflicting school and health facility schedules, inadequate TB screening in school health units (sick bays) as well as health worker gaps in TB screening among adolescents (Table 1).
Adolescents, especially those in school, have to decide between attending the school routine or miss school for visits to the health care facilities for healthcare. The adolescents interviewed raised this as a barrier to accessing a TB diagnosis. They noted that visiting health facilities means absconding from the school routine and when this is not possible, they do wait for holidays before they can seek care. Indeed, in some schools, school absence policies could stand in the way of health care seeking as has previously been documented. ${ }^{11}$ Previous studies have documented inaccessibility of health centres for young people with majority of the health centres operating during school hours and being closed on weekends when adolescents can access them. ${ }^{12}$ Premised on this, the WHO roadmap towards ending TB in children and adolescents calls for adolescent-friendly services with minimal disruption of education. ${ }^{8}$ Provision of adolescent services on weekends, improvement in school health services and creation of adolescent days at health facilities might render TB services more friendly to adolescent needs. The Uganda adolescent health policy guidelines and services standards document recommends linkages between school and health facilities but is silent on allowing flexible schedules at school to enable adolescents access care. ${ }^{13}$ It only comes out strongly to mention allowing flexible schedules at school for the adolescents living with HIV. ${ }^{13}$

Most schools are supposed to have a health unit (sickbay) manned by a nurse at a minimum. The school health system is an important aspect of the health care system and is necessary for ensuring healthy students/pupils and ultimately optimisation of learning. Despite the presence of sickbays in schools, adolescents felt the nurses were not doing enough to investigate them further even when they presented to the sickbay. Stories of unequipped sickbays in Ugandan schools continue to dominate discussions despite the existence of a school health policy which also cites gaps in human resource in the school sickbays. ${ }^{14}$ The school sick bays offer a wonderful opportunity to initiate the TB investigation cascade if the nurses could take a detailed TB history. Studies done have shown that school-based adolescent health clinics and school-based health centres increase utilisation and access to care for medical conditions ${ }^{14-17}$

Health worker knowledge gaps were also noted by the health workers. Some health workers do not think of possibility of TB even when the adolescents present with cough symptoms. This they attributed to the fact that they thought TB is not common in adolescents who are not HIV 
Table I Emerging Themes and Quotes from the Focus Group Discussions

\begin{tabular}{|c|c|}
\hline Themes & Quotes \\
\hline \multicolumn{2}{|r|}{ Adolescents } \\
\hline Knowledge and risk of TB & $\begin{array}{l}\text { "Some of our friends engage in drinking alcohol and smoking which can lead to contracting TB." I9- } \\
\text { year-old Male; Entebbe Hospital } \\
\text { "The places we move in such as bars, slums, and crowded people eg in hospitals exposes someone } \\
\text { to TB." I7-year-old Female; Entebbe Hospital } \\
\text { "For me when I got the cough, I used herbal medicine and I became ok." I5-year-old Male; Entebbe } \\
\text { Hospital }\end{array}$ \\
\hline Conflicting school schedules & $\begin{array}{l}\text { "Musawo, as I said it may be a chance, you may come early .... like now I came at around } 9 \text { am, but } \\
\text { by now (I:30 pm), the pharmacy is still closed thus you cannot get medication so I have been here } \\
\text { waiting, by now I cannot go to school so I have missed school today." I8-year-old Male; Luwero } \\
\text { Health Centre IV } \\
\text { "If they don't work on me, I may take my time because I also have to go to school, probably I will } \\
\text { come back in the next holidays because I have tried to come in this holiday when it has just started" } \\
\text { I8-year-old Female; Luwero Health Centre IV }\end{array}$ \\
\hline $\begin{array}{l}\text { The limited capacity of the school health } \\
\text { system to diagnose TB }\end{array}$ & $\begin{array}{l}\text { ".... another thing, some of us find ourselves at school. When that cough gets you.....you } \\
\text { know at school we have the health workers cough can get you and gets you for a long period } \\
\text { or even when it has just got you and you go to say the school nurse, they do not care knowing } \\
\text { much, they just ask you what is paining you and you say cough then she gives you drugs and } \\
\text { then you stay there and they do not even allow you to go home to get to a hospital." I7-year- } \\
\text { old Female; Gombe hospital }\end{array}$ \\
\hline Health systems challenges & $\begin{array}{l}\text { ".... the problem is that when you reach hospital, every health worker has their attitude, some are easy, } \\
\text { and others are difficult. For some you describe your situation and how you feel, then they back at you that } \\
\text { you have taken long without going to hospital and how you have been going to die. This demotivates for one } \\
\text { to come back." I8-year-old male from Nakaseke Health Centre IV } \\
\text { ".... for me if I get the right guidance and counselling, providing sputum may not be a problem as long as } \\
\text { I have it, so the counselling would help to know why am giving the sputum" I7-year-old Female; Entebbe } \\
\text { Hospital }\end{array}$ \\
\hline Fear of a TB diagnosis & $\begin{array}{l}\text { "I was told I don't have TB. But also on giving me the results, I was fearful.......but they checked } \\
\text { when I was fine, because I thought if they find me having TB, I may also have HIV" I6-year-old } \\
\text { Female; Entebbe Hospital } \\
\text { "For me the way they talk about TB treatment; I fear going for TB check-up. In our village they say } \\
\text { that they inject you } 60 \text { injections as medicine for TB. Eehheehhheehh, people fear TB treatment } \\
\text { that's why I fear." I6-year-old Male; Nakaseke Health Centre } \\
\text { "for the adolescents, people don't want to see them holding the sputum container, you even hide } \\
\text { behind buildings to try and produce the sputum" I8-year-old Male; Nakaseke Health Centre }\end{array}$ \\
\hline Loss of trust in public health care systems & $\begin{array}{l}\text { ".... for me what took me to the clinic is that when you go to government hospitals, they tell } \\
\text { you there is no medicine and tell you to go buy at private pharmacies, and usually the medicines } \\
\text { are very expensive, and also the lines there are long and you find yourself coughing in people, } \\
\text { they all look at you and you feel out of place. So a person who goes to the clinic may be better } \\
\text { because, they get the services faster though they have to pay money." I7-year-old Female; } \\
\text { Entebbe Hospital }\end{array}$ \\
\hline Role of parents & $\begin{array}{l}\text { "For me they support me, even today they pushed me to come for checkup." I6-year-old Male; } \\
\text { Luwero hospital } \\
\text { "for me, its self-initiated, my parents seem not to care." } 19 \text { year-old Male; Luwero hospital } \\
\text { "they should sensitize and educate parents about adolescent TB, they can also go to schools....... } \\
\text { Parents are key educators of their children." } 19 \text { year old female; Entebbe hospital }\end{array}$ \\
\hline
\end{tabular}


Table I (Continued).

\begin{tabular}{|c|c|}
\hline Themes & Quotes \\
\hline \multicolumn{2}{|r|}{ Health care workers } \\
\hline TB exposure at schools & $\begin{array}{l}\text { "Adolescents most cases are at school, they are always at school, imagine at school there is } \\
\text { a biggest exposure, they are at risk, the dormitory is overcrowded, someone may be coughing } \\
\text { without knowing whether he/she has TB. So all those children are at risk of getting TB, they are } \\
\text { sleeping in the same dormitory, the dormitory is congested, may he/she does not know because } \\
\text { they are lacking knowledge concerning TB." Out Patient Department (OPD) TB nurse. }\end{array}$ \\
\hline Uncooperative adolescents & $\begin{array}{l}\text { "At times when they come to the hospitals, they do not say all. At times they hide this away from } \\
\text { their parents. Even where they stay at times you find they have lived with someone who has ever } \\
\text { had TB. Even as you take their history...ok at times as you take their history, you find they are } \\
\text { reserved. Even when you request for a lab test, some of them are a bit hesitant to give a sample. At } \\
\text { times they want to be followed up all the way." OPD Nurse. } \\
\text { "..........in trying to provide a mask, they look at it as being stigmatizing. Even when we explain why } \\
\text { the we use a mask. Even when you give them and they are not escorted by an adult, he will have to } \\
\text { pocket his mask...... he asks why is it only me putting on a mask. He may even reach the lab and sit } \\
\text { down." A TB nurse mentioned. }\end{array}$ \\
\hline $\begin{array}{l}\text { Health worker inadequacies regarding TB } \\
\text { diagnosis in adolescents }\end{array}$ & $\begin{array}{l}\text { "I also think that we people who diagnose TB miss out on adolescents who have TB because we } \\
\text { always think that one for someone to have TB, they must have low immunity or other } \\
\text { accompanying factors, which is not easily thought of about adolescents. I can only think about TB } \\
\text { when the adolescent has HIV otherwise, you be like nowhere this little girl may have TB so we } \\
\text { normally treat other upper respiratory infection not thinking about TB." A clinician said. } \\
\text { "This is a big hospital, patients come with a burden of diseases, so these patients need to find us } \\
\text { (health workers) with a sober mind, not in disorganised mode." A nurse said. } \\
\text { "The biggest challenge I see since I came here is low interest in TB among staff, you find that every } \\
\text { time you get the TB patient, you call the TB focal person, every time the TB focal person, most of } \\
\text { these our colleagues, I do not know, but we fear a lot TB, we are not comfortable handling TB } \\
\text { patients." A nurse at OPD said. } \\
\text { "Also one of the things they worry about is the treatment, because there is still a myth in } \\
\text { a community that treatment for TB takes a whole year, and it is tough, so it's usually their fears, for } \\
\text { how long am I going to take medicine". A clinical officer reported. }\end{array}$ \\
\hline
\end{tabular}

positive. Much as HIV has been documented as a major risk factor for $\mathrm{HIV}$, the incidence of $\mathrm{TB}$ in a cohort of HIV-positive adolescents was found low, ${ }^{18,19}$ thus requiring health workers to explore other risk factors. Health worker knowledge gaps have been documented in previous studies and could complicate TB control. ${ }^{20-22}$

The health care workers noted TB diagnosis in adolescents was challenging given adolescents withhold information that could help them work towards making a diagnosis. It has been reported adolescents keep vital information to themselves when the confidentiality of the information given to the health worker is not assured, and even forego care when they feel the confidentiality/privacy is not assured. Moreover, people at public health facilities in Uganda are less likely to be evaluated for TB if they do not disclose TB symptoms to health workers. ${ }^{23}$ Provision of adolescent friendly services while ensuring identification and minimisation of the barriers that prevent young people from opening up to health care workers has potential to improve TB care. In Uganda, the adolescent health policy guidelines and services standards exist. ${ }^{13}$ These mention two levels of training of service providers in provision of adolescent health services, ie, preservice and inservice trainings. ${ }^{13}$ Despite the guidance, services in some if not all parts of Uganda might not entirely be youth friendly. ${ }^{24}$

The study also revealed other challenges that could complicate TB care in adolescents despite the challenges not being unique to adolescents. These include loss of trust in public facilities as they would be asked to go buy medicines, yet they expected them to be free. Some of the health services may be expensive and beyond their 
reach. This complicates care given that young people depend on adults for financial support. ${ }^{12}$ The WHO roadmap recommends that child and adolescent TB-related services (including diagnostic services) are made free of charge. ${ }^{8}$

Improving TB diagnosis in adolescents has the potential to improve adolescent health and the health of the general population by cutting the cycle of TB transmission. Based on our analysis, several factors must be considered in improving TB care among adolescents. These include the development and implementation of interventions that have minimal disruptions on school schedules and yet increase accessibility to care, provision of adolescent-friendly services and building capacity of health care workers in the provision of adolescentfriendly services.

\section{Limitations}

This study had several limitations. We recruited adolescents attending health facilities and not adolescents in the community. This may have led to selection bias, as the analysis was limited to adolescents already comfortable with attending facilities. We would also have ideally supplemented interviews with health workers at the school sickbays. Second, the data collection tool was not specific to adolescents and many of the issues identified are not unique to adolescents. Also, we note that this qualitative design cannot produce generalizable evidence, calling for larger studies of community samples of at-risk adolescents.

\section{Conclusion}

Adolescents present unique challenges that need to be addressed if TB diagnosis is to improve. These challenges could be handled by interventions that lead to minimal disruptions on school schedules, provision of adolescentfriendly services and intervention to build capacity of health care workers in the provision of adolescentfriendly services.

\section{Acknowledgments}

We acknowledge the contribution of the study participants, administration of the study facilities and research administrators at Makerere University Lung Institute.

\section{Disclosure}

The authors report no conflicts of interest in this work.

\section{References}

1. Tuberculosis-good progress, but not enough. UNAIDS; 2020. Available from: https://www.unaids.org/en/resources/presscentre/fea turestories/2020/march/20200323_tb. Accessed October 27, 2021.

2. Global tuberculosis report 2021. World Health Organization; 2021. Available from: https://www.who.int/teams/global-tuberculosisprogramme/tb-reports/global-tuberculosis-report-2021. Accessed October 25, 2021.

3. Jeremiah K, Lyimo E, Ritz C, et al. Prevalence of Mycobacterium tuberculosis infection as measured by the QuantiFERON-TB Gold assay and ESAT-6 free IGRA among adolescents in Mwanza, Tanzania. PLoS One. 2021;16(6):e0252808. doi:10.1371/JOURNAL. PONE.0252808

4. Guix-Comellas EM, Rozas L, Velasco-Arnaiz E, Morín-Fraile V, Force-Sanmartín E, Noguera-Julian A. Adherence to antituberculosis drugs in children and adolescents in a low-endemic setting: a retrospective series. Pediatr Infect Dis J. 2017;36(6):616-618. doi:10.1097/INF.0000000000001508

5. De Pontual L, Balu L, Ovetchkine P, et al. Tuberculosis in adolescents: a French retrospective study of 52 cases. Pediatr Infect Dis J. 2006;25(10):930-932. doi:10.1097/01.INF.0000237919.53123.F4

6. Moon TD, Nacarapa E, Verdu ME, et al. Tuberculosis treatment outcomes among children in rural Southern Mozambique: a 12-year retrospective study. Pediatr Infect Dis J. 2019;38(10):999-1004. doi:10.1097/INF.0000000000002435

7. The Uganda National tuberculosis prevalence survey, 2014-2015 survey report Ministry of Health, Republic of Uganda; 2015. Available from: https://www.health.go.ug/cause/the-uganda-national-tuberculosis-preva lence-survey-2014-2015-survey-report/. Accessed November 24, 2021.

8. New Roadmap towards ending TB in Children and Adolescents. World Health Organization; 2018. Available from: https://www. who.int/news/item/25-09-2018-new-roadmap-towards-ending-tb-inchildren-and-adolescents. Accessed September 17, 2021.

9. Sawyer SM, Afifi RA, Bearinger LH, et al. Adolescence: a foundation for future health. Lancet. 2012;379(9826):1630-1640. doi:10.1016/S0140-6736(12)60072-5

10. MEDBOX; 2017. Uganda: manual for management and control of tuberculosis and leprosy. Available from: https://www.medbox.org/ document/uganda-manual-for-management-and-control-oftuberculosis-and-leprosy\#GO. Accessed October 27, 2021.

11. Donald PR, Beyers N, Rook GAW. Adolescent tuberculosis. S Afr Med J. 1996;86(3):231-233.

12. Veedu PT. Pediatric vs adult pulmonary tuberculosis: a retrospective computed tomography study. World J Clin Pediatr. 2013;2(4):70. doi:10.5409/wjcp.v2.i4.70

13. Adolescent Health Policy Guidelines and Service Standards. Ministry of health knowledge management portal; 2012. Available from: http:// library.health.go.ug/publications/adolescent-health/adolescent-healthpolicy-guidelines-and-service-standards. Accessed October 27, 2021.

14. Kimera E, Vindevogel S, De Maeyer J, et al. Challenges and support for quality of life of youths living with HIV/AIDS in schools and larger community in East Africa: a systematic review. Syst Rev. 2019;8(1):1-18. doi:10.1186/S13643-019-0980-1

15. Murphy DA, Rotheram-Borus MJ, Joshi V. HIV-infected adolescent and adult perceptions of tuberculosis testing, knowledge and medication adherence in the USA. AIDS Care. 2000;12(1):59-63. doi:10.1080/09540120047477

16. Bobba GV, Venugopal V. A study on awareness of Tuberculosis amongst patients attending a rural health center in Tamilnadu, India. Int J Community Med Public Health. 2017;4(4):1195-1198. doi:10.18203/2394-6040.IJCMPH20171348

17. Boum Y, Atwine D, Orikiriza P, et al. Male Gender is independently associated with pulmonary tuberculosis among sputum and non-sputum producers people with presumptive tuberculosis in Southwestern Uganda. BMC Infect Dis. 2014;14(1):1-8. doi:10.1186/S12879-014-0638-5 
18. HIV and tuberculosis co-infection programmes. Avert; 2020. Available from: https://www.avert.org/professionals/hivprogramming/hiv-tb-coinfection. Accessed September 18, 2021.

19. Frigati LJ, Wilkinson KA, le Roux S, et al. Tuberculosis infection and disease in South African adolescents with perinatally acquired HIV on antiretroviral therapy: a cohort study. J Int AIDS Soc. 2021;24 (3):e25671. doi:10.1002/JIA2.25671

20. Ashton J, Dickson K, Pleaner M. Evolution of the NAFCI in South AFRICA. Vol. 1. Who; 2009:1-10.

21. James S, Pisa PT, Imrie J, et al. Assessment of adolescent and youth friendly services in primary healthcare facilities in two provinces in South Africa. BMC Health Serv Res. 2018;18(1):1-10. doi:10.1186/ S12913-018-3623-7
22. SAFE TEENS: facilitators of and barriers to adolescent preventive care discussions. Available from: https://pubmed.ncbi.nlm.nih.gov/ 18247179/. Accessed September 18, 2021.

23. Kakame KT, Namuhani N, Kazibwe A, Bongomin F, Baluku JB, Baine SO. Missed opportunities in tuberculosis investigation and associated factors at public health facilities in Uganda. BMC Health Serv Res. 2021;21(1):1-7. doi:10.1186/S12913-021-06368-6

24. Improve provision of youth-friendly health services in Kabale District. Population Reference Bureau; 2019. Available from: https://www.prb.org/wp-content/uploads/2019/01/eeda_uganda-factsheets-kabale.pdf\#: :text=Youth $\% 2$ Dfriendly $\% 20$ health $\% 20$ services $\% 20$ provide,locations $\% 20$ convenient $\% 20$ for $\% 20$ young $\% 20$ people. Accessed November 24, 2021.
Risk Management and Healthcare Policy

\section{Publish your work in this journal}

Risk Management and Healthcare Policy is an international, peerreviewed, open access journal focusing on all aspects of public health, policy, and preventative measures to promote good health and improve morbidity and mortality in the population. The journal welcomes submitted papers covering original research, basic science, clinical \& epidemiological studies, reviews and evaluations,
Dovepress

guidelines, expert opinion and commentary, case reports and extended reports. The manuscript management system is completely online and includes a very quick and fair peer-review system, which is all easy to use. Visit http://www.dovepress.com/testimonials.php to read real quotes from published authors. 